\title{
ОЦЕНКА ТОКСИЧНОСТИ СЛОЖНЫХ КОМПОСТОВ МЕТОДОМ БИОТЕСТИРОВАНИЯ 1
}

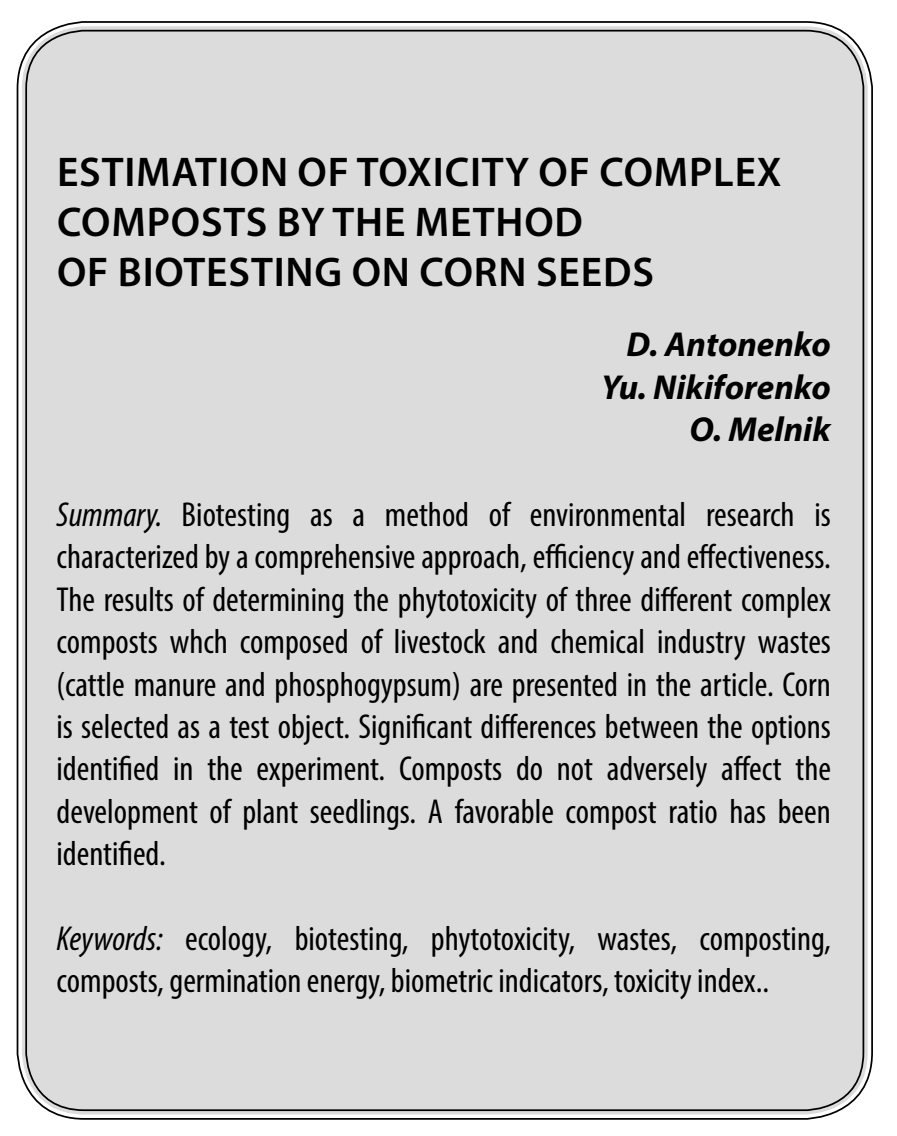

Б иотестирование - это один из видов биоиндикации, суть которого заключается в оценке реакции живых организмов на изменяющиеся условия среды. В качестве тест-объектов могут выступать различные живые организмы - от низших до высших уровней организации. Они как маячки сигнализируют о токсичности и непригодности среды обитания. Этот метод весьма эффективен и оперативен, может заменить сложные длительные химические анализы. Часто применяется для оценки токсичности почвы, отходов, донных отложений, вод и других объектов (Мельник, Яковина, 2016; Антоненко, Горбань, 2018; Антоненко, Белюченко, 2018; Никифоренко, 2018; Мельник, 2019).
Антоненко Дарья Алексеевна К.с.-х.н., доцент, Кубанский государственный аграрный университет имени И. Т. Трубилина

(2. Краснодар)

dasha-slav@rambler.ru

Никифоренко Юлия Юрьевна

К.б.н., дочент, Кубанский государственный аграрный университет имени И. Т. Трубилина (2. Краснодар) petuh_yulya@mail.ru

Мельник Ольга Александровна

К.б.н., дочент, Кубанский государственный аграрный университет имени И. Т. Трубилина (2. Краснодар) melnik_olga240781@mail.ru

Аннотация. Биотестирование как метод экологических исследований отличается комплексностью подхода, эффективностью и оперативностью. В статье приводятся результаты определения фитотоксичности трех разных вариантов сложных компостов, составленных из отходов животноводства и химической промышленности (навоза КРС и фосфогипса) в разном их соотношении. В качестве тест-объекта выбрана кукуруза. В опыте выявлены существенные различия в питательной ценности между вариантами. Компосты не оказывают негативного влияния на развитие проростков испытуемой культуры. Отмечено более благоприятное компонентное соотношение компоста.

Ключевые слова: экология, биотестирование, фитотоксичность, отходы, компостирование, компосты, энергия прорастания, биометрические показатели, индекс токсичности.

Оценка загрязнений с использованием живых организмов отличается комплексным подходом, поскольку биоиндикаторы реагируют на весь комплекс загрязнений; а химические и физико-химические способы оценки ориентированы на один конкретный элемент-загрязнитель.

На наш взгляд использование метода биотестирования при оценке токсичности отходов и компостов является подходящим экспресс-методом. В литературе встречаются похожие исследования (Михеева и др., 2014; Бойцова и др., 2017). Например, для оценки качества компоста китайскими учеными предлагается тест на всхожесть семян, который является мощным инстру-

' Исследования выполнены в рамках поддержки фундаментальных научных исследований по гранту (номер 19-416233033 р_мол_а) РФФИ и администрации Краснодарского края 


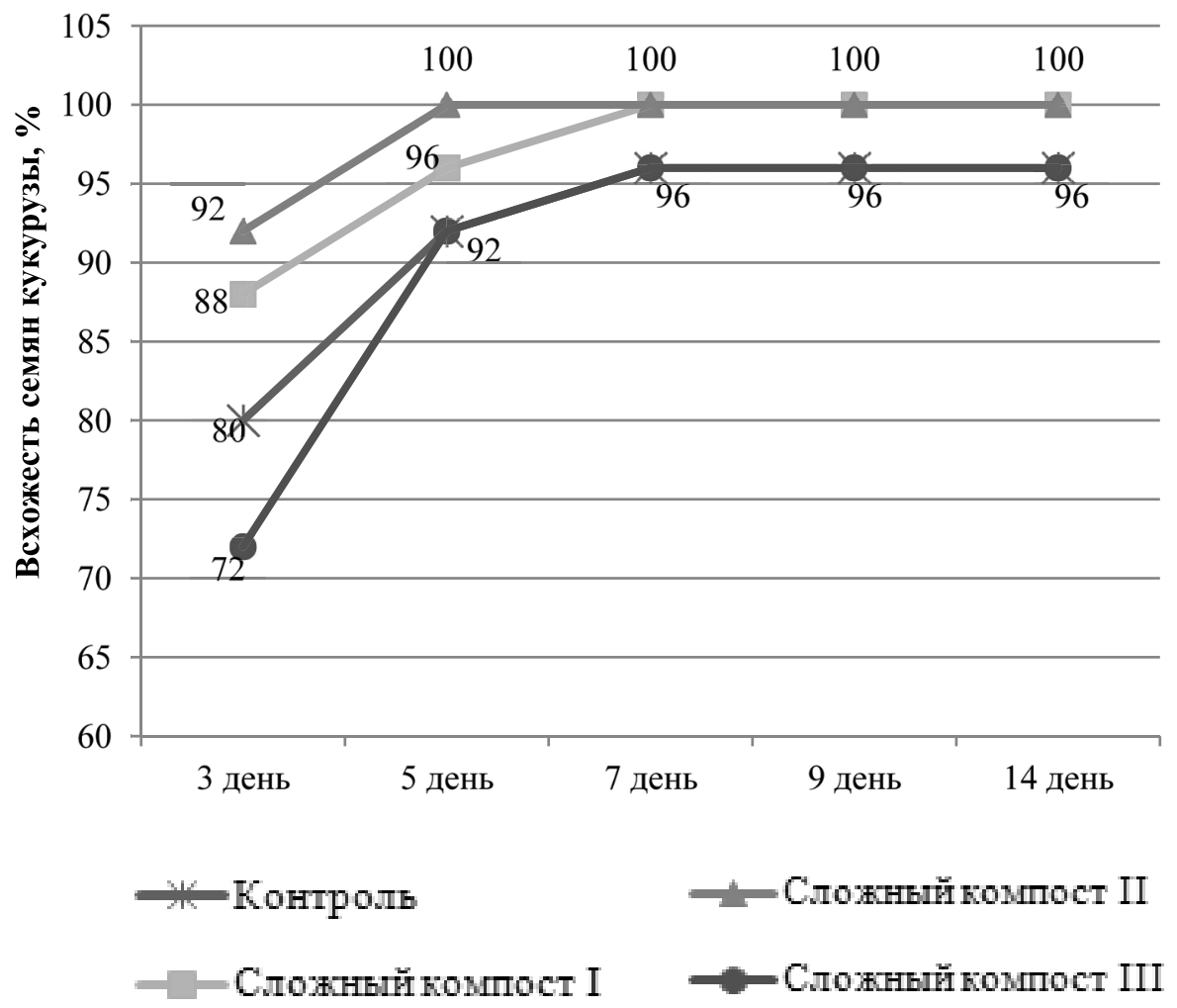

Рис. 1. Энергия прорастания семян кукурузы в результате биотестирования сложных компостов,\%

ментом для изучения токсичности компоста. В качестве модельного семени для исследования фитотоксичности компоста предлагается использовать китайскую капусту (Luo et al., 2018).

В нашей работе по оценке токсичности и экологической безопасности полученных компостов мы использовали растительный объект - семена кукурузы. Выбор культуры также связан с дальнейшим проведением полевого эксперимента по оценке воздействия различных доз компостов на рост и урожайность кукурузы. Лабораторный эксперимент позволил нам оценить не только токсичность компостов, но их влияние на начальный рост и развитие выбранного тест-объекта.

\section{Метолические аспекты исслеАований}

Для изучения особенностей формирования сложного компоста из полуперепревшего навоза КРС и фосфогипса был заложен опыт по компостированию, который включал 3 варианта. Три разных варианта компоста формировали в специальных емкостях для компостирования ( $\mathrm{V}=500$ л) путем смешивания двух основных отходов в различных соотношениях. Также с целью обеспечения лучшей аэрации в каждый из вариантов было добавлено одинаковое количество соломы люцерны.
Варианты компостов: 1) сложный компост I - полуперепревший навоз КРС + фосфогипс (в соотношении 5:1) + солома люцерны; 2) сложный компост II - полуперепревший навоз КРС + фосфогипс (в соотношении 7:1) + солома люцерны; 3) сложный компост III - полуперепревший навоз КРС + фосфогипс (в соотношении 9:1) + солома люцерны.

Компостирование проводили в весенне-летний период при температуре воздуха 20-30 ㄷ и благоприятных условиях увлажнения. Для более эффективного взаимодействия компонентов компоста поддерживали влажность субстратов на уровне $35-40 \%$ и обеспечивали поступление кислорода путем периодического перемешивания.

Биотестирование компостов проводили в виде лабораторных опытов в чашках Петри. В качестве объекта исследования были выбраны зерна кукурузы. Для полива при проращивании кукурузы использовали водную вытяжку из различных компостов (субстрат: вода $=1: 10$ ).

Опыт по биотестированию включал 4 варианта: 1) контроль - дистиллированная вода; 2) водная вытяжка из сложного компоста I; 3) водная вытяжка из сложного компоста II; 4) водная вытяжка из сложного компоста III. 
Таблица 1. Биометрические показатели растений кукурузы и их изменение в зависимости от варианта опыта

\begin{tabular}{|c|c|c|c|}
\hline День опыта & Вариант опыта & $\begin{array}{l}\text { Длина побега } \\
\text { кукурузы, см }\end{array}$ & $\begin{array}{l}\text { Длина основного корня } \\
\text { кукурузы, см }\end{array}$ \\
\hline \multirow{4}{*}{3 день } & Контроль & $0,78 \pm 0,04$ & $1,18 \pm 0,06$ \\
\hline & Сложный компост I & $0,91 \pm 0,04$ & $0,87 \pm 0,04$ \\
\hline & Сложный компост ॥ & $1,12 \pm 0,05$ & $0,95 \pm 0,05$ \\
\hline & Сложный компост III & $0,88 \pm 0,04$ & $0,64 \pm 0,04$ \\
\hline \multirow{4}{*}{5 день } & Контроль & $5,58 \pm 0,25$ & $4,27 \pm 0,20$ \\
\hline & Сложный компост I & $5,86 \pm 0,26$ & $4,21 \pm 0,21$ \\
\hline & Сложный компост ॥ & $6,87 \pm 0,32$ & $5,02 \pm 0,24$ \\
\hline & Сложный компост III & $5,74 \pm 0,28$ & $4,14 \pm 0,21$ \\
\hline \multirow{4}{*}{7 день } & Контроль & $7,36 \pm 0,35$ & $8,28 \pm 0,40$ \\
\hline & Сложный компост I & $8,46 \pm 0,40$ & $7,98 \pm 0,39$ \\
\hline & Сложный компост ॥ & $9,21 \pm 0,45$ & $9,04 \pm 0,44$ \\
\hline & Сложный компост III & $7,98 \pm 0,39$ & $7,76 \pm 0,40$ \\
\hline \multirow{4}{*}{9 день } & Контроль & $8,94 \pm 0,44$ & $11,48 \pm 0,54$ \\
\hline & Сложный компост I & $9,87 \pm 0,47$ & $12,70 \pm 0,63$ \\
\hline & Сложный компост ॥ & $10,84 \pm 0,53$ & $13,45 \pm 0,65$ \\
\hline & Сложный компост III & $8,98 \pm 0,44$ & $11,08 \pm 0,53$ \\
\hline \multirow{4}{*}{14 день } & Контроль & $10,74 \pm 0,52$ & $13,87 \pm 0,68$ \\
\hline & Сложный компост I & $12,78 \pm 0,62$ & $14,16 \pm 0,70$ \\
\hline & Сложный компост ॥ & $13,55 \pm 0,67$ & $15,14 \pm 0,75$ \\
\hline & Сложный компост III & $10,86 \pm 0,52$ & $12,54 \pm 0,61$ \\
\hline
\end{tabular}

Повторность опыта была 5-ти краткая; в каждую чашку Петри на фильтровальную бумагу раскладывали по 5 зерен кукурузы. Полив проводили в течение двух недель с интервалом 2-3 дня в количестве 20 мл. В период проведения лабораторного опыта велись регулярные измерения следующих показателей: всхожесть семян, длина побегов, длина корней. В конце опыта определяли биомассу растений в воздушно-сухом состоянии.

\section{Результаты исслеАований и их обсужАение}

Одним из важных показателей при проведении биотестирования на растениях является энергия прорастания и всхожесть семян. Энергия прорастания характеризует дружественность и скорость прорастания семян. Обычно она определяется в первые 3-4 дня проведения биотестирования. У нас в опыте отмечены более дружные всходы кукурузы в вариантах со сложным компостом II и сложным компостом I (92 и 88\%, соответственно). Минимальные значения этого показателя выявлены в варианте со сложным компостом III - только 72\% семян кукурузы проросли на 3 день опыта. На контроле энергия прорастания семян составила $80 \%$ (рисунок 1).

Всхожесть семян - количество нормально проросших семян за весь период проведения лабораторного опыта (14 дней). Результаты подсчета всхожести семян были на высоком уровне во всех вариантах опыта. При поливе вытяжками из сложных компостов | и || нормально проросли все семена (всхожесть 100\%). Причем полная всхожесть кукурузы в варианте со сложным компостом I отмечена на 5 день опыта, а в варианте со сложным компостом II - на 7 день опыта. Максимальная всхожесть на контроле выявлена на 7 день опыта и составила $96 \%$. Аналогичное прорастание семян характерно и для варианта со сложным компостом III (рисунок 1).

Первые результаты измерений биометрических показателей растений кукурузы проводили на 3 день лабораторного опыта. Выявлено, что на контроле (дистиллированная вода) длина основного корня кукурузы была больше по сравнению с компостами, тогда как длина побега наоборот - меньше. Далее разница между вариантами несколько поменялась. Так на 5день опыта максимальная длина побега отмечена в варианте со сложным компостом II, в остальных вариантах данный показатель был близок к контролю. Аналогичные изменения характерны и для длины основного корня кукурузы: максимум отмечен в варианте со сложным компостом II. Через неделю после закладки опыта рост побега при поливе водой несколько замедлился, тогда как при поливе вытяжками из компостов I и II - был интенсивнее. Длина побега кукурузы в варианте со сложным компостом III и на контроле через 14 дней опыта была примерно одинаковой (таблица 1). 
Таблица 2. Результаты расчета индекса фитотоксичности при биотестировании компостов

\begin{tabular}{|l|l|l|l|l|}
\hline Вариант опыта & $\begin{array}{l}\text { Длина } \\
\text { проростка, см (Ln) }\end{array}$ & $\begin{array}{l}\text { Длина } \\
\text { корешка, см (Lк) }\end{array}$ & ИФ & $\begin{array}{l}\text { Класс } \\
\text { токсичности }\end{array}$ \\
\hline Контроль & 10,74 & 13,87 & - & - \\
\hline Сложный компост I & 12,78 & 14,16 & 1,09 & норма \\
\hline Сложный компост II & 13,55 & 15,14 & 1,17 & $\begin{array}{l}\text { стимуляция } \\
\text { роста }\end{array}$ \\
\hline Сложный компост III & 10,86 & 12,54 & 0,95 & норма \\
\hline
\end{tabular}

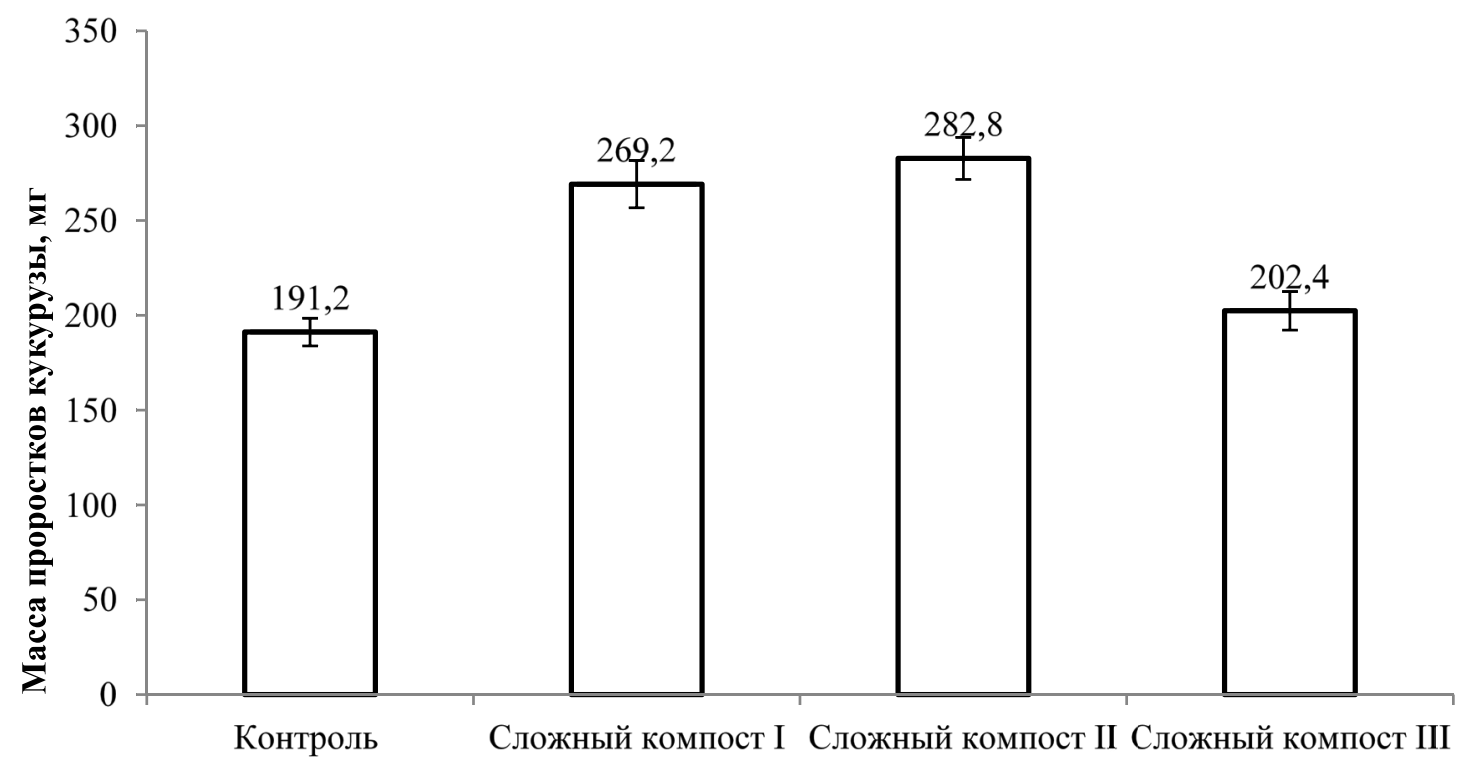

Рис. 2. Изменение массы проростков кукурузы в зависимости от компоста, мг (сухое вещество)

Длина основного корня на 9 и 14 день опыта была максимальной в вариантах со сложными компостами I и II. Отмечено, что корни в варианте со сложным компостом III развивались медленнее, на концах были незначительно повреждены, вероятно, из-за большего содержание органических веществ по сравнению с другими вариантами. Также в вариантах со сложными компостами I и II прослеживается обильный рост корневых волосков на основном и дополнительных корнях, что не выявлено на контроле и в варианте со сложным компостом III (таблица 1).

Если рассматривать два «похожих» варианта (сложный компост I и сложный компост ІІ), то лучшими показателями в ходе биотестирования выделяется сложный компост II, где соотношение навоза и фосфогипса 7:1. Так длина побега кукурузы в этих вариантах составила 12,8 и 13,6 см соответственно, а длина основного корня 14,1 и 15,1 см. Также для варианта II характерно наличие более длинных дополнительных корешков и обилие на них корневых волосков. По нашему мнению, заметный рост основного корня, дополнительных корешков и корневых волосков связан с добавлением в компост фосфогипса, содержащего значительную долю кальция.
Масса проростков кукурузы варьировала от 191 до 283 грамм. Причем максимум отмечен в варианте со сложным компостом II. Близкие показатели массы и несущественные различия выявлены между контролем и вариантом со сложным компостом III (191,2 и 202,4 грамм, соответственно) (рисунок 2).

В результате биотестирования выявлены однозначные изменения в длине проростка и основного корня кукурузы. Также видна заметная разница между вариантами по энергии прорастания и всхожести, массы надземной части растений. Сложные компосты I и II положительно влияют на начальный рост кукурузы. Токсичность этих удобрений не выявлена. Растения в варианте со сложным компостом III развивались иначе и биометрические показатели находились на уровне контроля. Для получения еще более наглядных результатов нами был рассчитан индекс фитотокстичности по формуле:

$$
\text { ИФ }=\frac{\left(L_{\pi}+L_{\mathrm{K}}\right)_{\text {опыт }}}{\left(L_{\mathrm{m}}+L_{\mathrm{K}}\right)_{\text {контроль }}}
$$

где $L_{n}$ - длина проростка, см; $L_{\kappa}$ - длина корешка, CM. 
Расшифровка: ИФ > 1,10- стимуляция роста; ИФ = 0,91-1,10- норма; ИФ =0,71-0,90-низкая токсичность; ИФ =0,50-0,70 - средняя токсичность; ИФ <0,50-высокая токсичность.

Индекс фитотоксичности определяет токсичность и ее степень. Расчеты индекса с использованием биометрических замеров кукурузы показали положительные результаты. Токсичность компостов не выявлена. Наоборот, отмечено положительное воздействие на рост проростков и корешков. Особенно это касается варианта сложный компост II, где индекс фитотоксичности указывает на стимуляцию роста растений. В вариантах сложных компост II и III стимуляции роста не отмечено, индекс фитотоксичности в норме (таблица 2).

Таким образом, результаты лабораторного опыта выявили изменения в начальном росте и развитии корешков кукурузы при поливе их водной вытяжкой из сложных компостов. Отмечено увеличение длины главного зародышевого корешка, количества боковых зародышевых корешков и корневых волосков. Биотестирование показало, что сложные компосты не угнетают рост побегов данной культуры. Наиболее благоприятное воздействие и стимуляция роста кукурузы отмечено в варианте со сложным компостом II.

\section{ЛИТЕРАТУРА}

1. Антоненко Д. А., Белюченко И.С. Оценка влияния отходов животноводства на окружающую среду методом биотестирования // Экологический вестник Северного Кавказа.— 2018. - Т. 14.— № 3.- С. 4-9.

2. Антоненко Д. А., Горбань М. А. Анализ фильтрационного осадка // Экологический вестник Северного Кавказа. — 2018. — Т. 14. — № 3.— С. 10-13.

3. Бойцова Л. В., Зинчук Е. Г., Моисеев К. Г., Пищик В. Н. Экологическая оценка почвогрунтов и сложных компостов методом биотестирования // Сборник научных трудов по материалам V Международной научной экологической конференции, посвященной 95-летию Кубанского ГАУ «Проблемы рекультивации отходов быта, промышленного и сельскохозяйственного производства». - 2017. - C. 332-335.

4. Мельник 0. А. Анализ данных, полученных при проращивании ярового рапса с использованием экстрактов из фосфогипса и навоза КРС // Экологический вестник Северного Кавказа.— 2019. - Т. 15.— № 34.— C. 43-46.

5. Мельник 0. А., Яковина Е. П. Влияние экстракций отходов на прорастание семян ярового рапса и горчицы белой // Международная научная экологическая конференция «Совмещенные посевы полевых культур в севообороте агроландшафта».— 2016.— - $282-286$.

6. Михеева И. Г., Пименова Е. В., Никитская Н. И. Биотестирование отходов ОАО «КамаБумПром» в лабораторном опыте // Материалы Всероссийской научно-практической конференции «Молодежная наука 2014: технологии, инновации». - 2014. - С. 279-281.

7. Никифоренко Ю. Ю. Почвенная мезофауна агроценозов под воздействием сложного компоста // Экологический вестник Северного Кавказа. - 2018. T. 14. - № 2. - C. 76-81.

8. Luo Y., Liang J., Zeng G., Chen M., Mo D., Li G., Zhang D. Seed germination for toxicity evaluation compost: its Roles, Problems and Prospects // Waste Management.2018. - T.71.-C. 109-114.

(c) Антоненко Дарья Алексеевна ( dasha-slav@rambler.ru ),

Никифоренко Юлия Юрьевна ( petuh_уulya@mail.ru ), Мельник Ольга Александровна ( melnik_olga240781@mail.ru ).

Журнал «Современная наука: актуальные проблемы теории и практики» 